\title{
ANALISIS BISNIS MODEL KANVAS PADA UMKM PENGOLAHAN MELINJO DI KECAMATAN LIMPUNG KABUPATEN BATANG
}

\author{
Sunendar ${ }^{1}$, Rifki Andi Novia ${ }^{1}$, Lutfi Zulkifli ${ }^{1}$ \\ ${ }^{1}$ Program Studi Agribisnis, Fakultas Pertanian, Universitas Jendral Soedirman
}

\begin{abstract}
Abstrak
Pengembangan ekonomi rakyat perlu diarahkan untuk mendorong perubahan nasional melalui pengembangan UMKM. UMKM emping melinjo merupakan sentra unit usaha terbanyak di Kabupaten Batang. Maka perlu analisa bisnis yang bisa diterapkan oleh wirausaha pengolahan melinjo salah satunya yaitu bisnis model kanvas. Tujuan penelitian ini untuk mengetahui analisa bisnis model yang tepat dan analisa orientasi kewirausahaan. Jenis penelitian menggunakan analisa deskriptif dengan pendekatan orientasi kewirausahaan dan model bisnis kanvas. Metode penelitian yang digunakan adalah kuantitatif dengan menggunakan teknik wawancara. Penelitian dilaksanakan pada bulan Agustus - Desember 2019. Respondennya yaitu pengusaha pengolahan emping melinjo sebanyak 30 Orang. Analisa menggunakan metode deskripsi dan model bisnis kanvas. Hasil peneltian menunjukan bahwa bisnis pengolahan melinjo memiliki sementasi konsumen yaitu konsumen luas. Preposisi nilai yaitu berdasarkan kinerja dengan mengutamakan kualitas agar tetap eksis dari tahun ke tahun. Saluran menggunakan pemasaran langsung dan tidak langsung. Hubungan konsumen dengan cara berkomunikasi langsung antara konsumer dengan pengusaha. Aliran uang bisnis pengolahan melinjo dari penjualan produk. Aktivitas utama dengan melalukan aktivitas produksi dan pemasaran. Sumberdaya utama yaitu bahan baku, tenaga kerja dan pemasaran. Mitra utama dengan pengrajin, pengusaha kemasan dan distibutor. Struktur biaya meliputi biaya variabel dan tetap.
\end{abstract}

Kata kunci: bisnis model kanvas, usaha kecil menengah, orientasi wirausaha

\begin{abstract}
The development of the people's economy needs to be directed to encourage national change through the development of MSMEs. MSMEs melinjo chips is the center of the largest business unit in Batang Regency. So the business analysis that can be applied by entrepreneurs processing melinjo one of them is the canvas business model. The purpose of this research is to know the right business model analysis and analysis of entrepreneurial orientation. This type of research uses descriptive analysis with an entrepreneurial orientation approach and canvas business model. The research method used is quantitative using interview and discussion techniques. The research was conducted in August-December 2019. The respondent was 30 people. Analysis using canvas description methods and business models. The results of the study show that melinjo processing business has customer segments namely mass customer. The value propositions are based on performance by prioritizing quality to remain exist from year to year. Channels use direct and indirect marketing. Customer relationship by communicating directly between consumers and entrepreneurs. Revenue streams the processing business from the sale of the product. Key activities by going through production and marketing activities. Key resources are raw materials, labor and marketing. Key partnership with craftsmen, packaging entrepreneurs and distibutors. Cost structure includes variable and fixed costs.
\end{abstract}

Keyword: business model canvas, MSMEs, entrepreneurial orientation 


\section{Pendahuluan}

Upaya pengembangan ekonomi rakyat perlu diarahkan untuk mendorong perubahan struktural dengan memperkuat kedudukan dan peran ekonomi rakyat dalam perekonomian nasional, pendekatan dalam ekonomi rakyat sebagai pengembangan UKM (Rizani, 2015). Usaha Mikro Kecil dan Menengah (UMKM) sebagai pengerak pengembangan potensi wilayah yang berbasis ekonomi kerakyatan (Irawan, 2015). Usaha kecil memiliki peranan dalam pertumbuhan dan pergerakan ekonomi suatu negara (Urata, 2000), seperti halnya yang terjadi di Indonesia. Kontribusi usaha kecil dapat meningkatkan pendapatan negara, banyak menyerap tenaga kerja, pemerataan kesejahteraan, dan penggerak ekonomi kerakyatan.

Potensi UMKM dijadikan pemerintah Indonesia untuk mempercepat pembangunan negara(Haliq, 2017). Oleh karena itu pemerintah kabupaten Batang dengan jumlah UMKM yang ada di Dinas Perindustrian, Koperasi dan UMKM yang tersaji pada tabel 1 ini menunjukan salah satu unggulan untuk menaikan perekonomian daerah.

Tabel 1

UMKM di Kabupaten Batang tahun 2017

\begin{tabular}{lr}
\hline Jenis UMKM & Unit usaha \\
\hline Emping melinjo & 6250 \\
Bata merah & 362 \\
Ikan pindang & 225 \\
Keripik singkong & 215 \\
Madu & 198 \\
\hline
\end{tabular}

Sumber : Dinas Perindustrian, Perdagangan, Koperasi dan UMKM Kabupaten Batang, tahun 2017

UMKM pengolahan melinjo menjadi unit usaha terbanyak di kabupaten Batang. Hal ini karena potensi SDA yang ada dan SDM terampil mejadi satu nilai tambah pada pengolahan melinjo. Biji melinjo juga memiliki gizi yang baik untuk tubuh (Tatefuji et al, 2014). Melinjo mudah untuk diolah menjadi beberapa makanan. Oleh karenanya pemerintah kabupaten Batang melakukan pemberdayaan kepada wirausaha kecil yang tergabung dalam kelompok untuk berwirausaha. Program ini dijadikan salah satu kebijakan pemerintah daerah kabupaten batang melalui one village one product (OVOP). Pemberdayaan yang dibentuk secara kelompok dengan mengajak wirausaha dalam mengolah melinjo ini dapat meningkatkan perekonomian keluarga.

Peningkatan kemampuan wirausaha menjadikan kegiatan bisnis memerlukan adanya model bisnis, agar terarah dan berkelanjutan usahanya. Strategi usaha yang dijalankan oleh perusahaan tidak akan dapat berjalan maksimal jika tidak didasari oleh pengkajian dan perumusan model bisnis yang tepat. Model bisnis merupakan hubungan antara keunggulan produk dengan sumberdaya yang dimiliki wirausaha. Kegiatan yang dilakukan dalam upaya menambah nilai tambah produk untuk menarik konsumen sehingga menghasilkan keuntungan. Strategi berkaitan dengan persaingan kompetitif dan pendekatan bisnis, sementara model bisnis perusahaan berkaitan dengan apakah pendapatan dan biaya yang mengalir dari strategi menunjukan kelayakan bisnis. Terdapat enam kerangka model bisnis yang salah satunya dapat diterapkan untuk mendeskripsikan, memahami, dan potensial untuk inovasi model bisnis yaitu pelayanan, strategi audit, strategi penjelajahan, dan intelektual Penerapan bisnis model kanvas di Indonesia masih baru diterapkan oleh beberapa wirausaha, oleh karenanya penelitian UMKM yang menerapkan bisnis model kanvas diperlukan untuk menunjang orientasi wirausaha dalam menjalankan kegiatan bisnisnya. Orientasi wirausaha yang baik akan menghasilkan kegiatan bisnis yang menambah keuntungan. Penelitian yang ditujukan untuk menganalisa pengaruh orientasi wirausaha terhadap wirausaha emping 
melinjo dan menganalisa bisnis model kanvas yang bisa diterapkan oleh wirausaha emping melinjo.

Kewirausahaan adalah karakter seorang yang suka membangun usaha dikemudian hari (Murni et al. 2014). Pendapat tersebut di kuatkan dalam penelitian Rosmasari (2019) dengan lima penjelasan yaitu: 1) kewirausahaan adalah gambaran kualitas pribadi yang memungkinkan untuk tampil dalam pembuatan keputusan yang konsekuensinya masih dalam jangkauannya, 2) wirausaha memiliki informasai yang lebih baik atau paling tidak lebih relevan pada perkembangan usaha daripada orang lain, 3) wirausaha memiliki motivasi pada kepentingan pribadi atau wirausaha menjalankan bisnis semata-mata untuk memkasimalkan keuntungan yang didapatkan dari sejumlah usaha, 4) sifat wirausaha lebih prcaya bahwa usahanya benar sementara orang lain salah dan 5) wirausaha berusaha membuat pasar untuk usahanya dan lainnya. Menurut Istiyanti dan Kamardiani (2017) Usaha emping melinjo merupakan usaha berbasis keterampilan tangan pengrajin, semakin lama seorang wirausaha menjalankan usahanya, maka akan terlihat semakin baik kualitas dan pengelolaan usaha emping melinjo, pengaruh faktor usia dan pengalaman usaha menjadi penentu pengelolaan usaha. skala usaha yang menunjukkan kategori sebuah usaha dapat dikelompkkan berdasarkan kriteria usaha mikro, kecil, dan menengah

Model bisnis memudahkan wirausaha untuk merencakan dan mengambil keputusan dalam menjalankan kegiatan usahany. Menurut Alexander Osterwalder dan Yves Pigneur dalam Priyono (2015) mengatakan bahwa Model bisnis dapat dijelaskan dengan sangat baik melalui sembilan blok bangun dasar yang memperlihatkan cara berfikir tentang bagaimana cara perusahaan menghasilkan uang. Adapun penjelasan dari ke sembilan elemen di atas yaitu sebagai berikut:

1. Key Partnership (Mitra Kunci) Dalam dunia industri (bisnis), perusahaan tidak bisa berkembang dan menjalankan usahanya tanpa adanya beberapa mitra yang diajak kerja sama, begitu pun di industri kopi. Perusahaan atau UMKM yang bergerak dalam industri kopi sangat bergantung kepada beberapa mitra

2. Key Activities (Aktivitas kunci) Yang dimaksud aktivitas kunci adalah kegiatan yang menentukan keberhasilan suatu model bisnis.

3. Key Resources (Sumber daya Utama) Sumber daya kunci menggambarkan asset-asset penting yang menentukan keberhasilan pengoperasian model bisnis.

4. Value Propositions (Proposisi Nilai) Value Propositions sangat penting untuk diterapkan, karena hal ini akan menjadikan suatu produk atau jasa menjadi lebih menarik dan unik dibandingkan produk lainnya. Beberapa jenisnya yaitu :

a) Produk Paling Baru (Newness Produck).

Produk dengan value ini akan mampu bersaing dengan berbagai inovasi produk terbaru pada masing-masing kelasnya. Biasanya bisnis yang memiliki value seperti ini mampu menghasilkan produk untuk jenis segmen kelas menengah ke atas.

b) Produk Paling Murah/Hagar Terjangkau (Price).

Produk seperti ini melakukan kebalikan dari sebelumnya. Bisnis akan berinovasi, namun dalam hal menekan biaya produksi, sehingga biaya dapat menjadi semakin terjangkau dan menjadi semakin lebih murah. Target pasar yang ingin segera dituju adalah dari kalangan menengah kebawah yang lebih sensitif terhadap harga pasar.

c) Produk Paling Unik (Uniqueness Product).

Merupakan produk yang mampu out of the box. Keunikan yang dimiliki yang mampu untuk menjadikan konsumen bersedia untuk megeluarkan uangnya dalam menikmati keunikan dari produk tersebut. 
d) Kinerja (Performance).

Produk seperti ini akan bisa menjadi lebih fokus terhadap kinerja yang lebih baik .Kinerja yang lebih responsif atau semakin cepat tanggap merupakan salah satu parameter yang telah diterapkan dalam produk ini.

e) Faktor Kemudahan (Accessibility).

Sebisa mungkin produk atau jasa yang telah dihasilkan terdapat disekitar konsumen, sehingga semakin memudahkan akses dari para konsumen untuk mendapatkan atau menggunakan produknya.

5. Customer Relationship (Hubungan dengan Pelanggan) Pembinaan hubungan dengan pelanggan bertujuan untuk mendapatkan pelanggan baru,mempertahankan pelanggan lama, dan menawarkan produk dan jasa lama atau baru kepada pelanggan lama.

6. Channel (Saluran) Saluran (Channel) adalah elemen yang menyatakan bagaimana organisasi berkomunikasi dengan segmen pelanggannya dan menyampaikan proposisi nilainya.

7. Customer Segments (Segmen Pelanggan) Segmen pelanggan adalah pihak tertentu yang menggunakan jasa atau produk dari organisasi sesuai dengan kebutuhannya.

8. Cost Structure (Struktur Biaya) Struktur biaya menggambarkan semua biaya yang muncul setelah dioperasikannya model bisnis ini.

9. Revenue Streams (Aliran Dana Masuk) Aliran dana masuk menggambarkan sebagaimana organisasi memperoleh uang dari setiap segmen pelanggan.

\section{Metode Penelitian}

Penelitian ini dilaksanakan di Kecamatan Limpung, Kabupaten Batang Jawa Tengah. Pemilihan lokasi penelitian dilakukan secara purposive (sengaja) dengan pertimbangan bahwa lokasi tersebut merupakan sentra industri pengolahan melinjo dan wirausaha mikro, kecil dan menengah yang masih aktif pada industri pengolahan melinjo.

Data yang digunakan untuk penelitian ini adalah data primer dan data sekunder. Data primer diperoleh dari kuesioner dan wawancara secara langsung dengan pengusaha pengolahan melinjo mengenai orientasi wirausaha. Data sekunder didapatkan melalui kajian studi pustaka dan literatur baik dari dinas terkait maupun penelitian yang ada.

Penentuan sampel dalam penelitian ini menggunakan teknik purposive sampling. Sampel ditentukan berdasarkan beberapa kriteria yaitu wirausaha pengolahan emping melinjo yang aktif berkegiatan disaat penelitian dan usaha mikro, kecil dan menengah pengolahan emping melinjo. Pengambilan responden wirausaha emping melinjo sebanyak 30 wirausaha umkm emping melinjo

Metode analisis menggunakan deskriptif analisis yang menjabarkan orientasi kewirausahaan dari 5 dimensi menurut Lumpkin dan Dess (2001). Analisis deskripsi digunakan untuk menjelaskan data yang sudah dikumpulkan untuk menentukan pengambilan keputusan dalam penelitian (Sugiono, 2011).

Menurut Azhar et all (2017) menjelaskan bisnis model menggunakan metode business model canvas (BMC) yang digunakan untuk menganalisa usaha yang dijalankan oleh wirausaha pengolahan emping melinjo. Identifikasi terhadap kesembilan unsur BMC yaitu Customer Segments (CS), Value Propositions (VP), Channels (CH), Customer Relationships (CR), Revenue Streams (RS), Key Resources (KR), Key Activities (KA), Key Partnerships (KP), dan Cost Structures (CS) diperlukan untuk mengetahui sasaran yang ingin dicapai organisasi 
menurut tujuan yang akan dicapai. Untuk menjaga keseimbangan bisnis yang dijalankan ( Priyono, 2015)

Penciptaan proposisi nilai baru pada perancangan model bisnis dimasa depan berupa program hiburan eduwisata untuk anak dan keluarga di Lokawisata Baturaden memengaruhi setiap unsur bisnis model kanvas, yaitu terjadi penambahan dalam hal sumber daya utama yang dimiliki, aktivitas kunci yang dilakukan, mitra kerjasama, dan aliran pendapatan yang masuk (Azhar, suparno, \& djohar, 2017). Menurut Priyono (2015) menunjukan kalau bisnis toko Moi Collection memiliki customer segment yang memiliki ciri tertentu sehingga pemasaran menjadi lebih efektif dan efisien. Orientasi kewirausaha yang baik akan berpengaruh pada kinerja usaha pengolahan melinjo di Kabupaten Batang. (Rosmasari, 2019). Dalam pemasaran emping melinjo di Kabupaten Bantul memiliki rantai yang panjang terdiri dari petani, pedagang biji melinjo, produsen, pedagang pengumpul, pedagang besar, pedagang pengecer, konsumen, produsen kemasan, buruh produksi, buruh gendong, dan penyedia kayu bakar (Sunendar, 2018).

\section{Hasil dan Pembahasan}

\section{Orientasi kewirausahaan}

Orientasi wirausaha pengolahan melinjo berkaitan erat pada kerangka yang selama ini dijalankan oleh wirausaha. Orientasi wirausaha yang terdiri dari lima dimensi yaitu proaktif, inovatif, agresif kompetitif, pengambilan risiko dan otonomi. Hal ini dapat dijelaskan bahwa sikap proaktif para wirausaha untuk selalu bergerak maju dan berusaha bersaing dengan wirausaha lainnya. Para wirausaha berusaha untuk selalu menjualkan produk emping melinjo dengan kualitas yang terbaik, oleh karenanya wirausaha selalu berlomba berusaha untuk selalu meningkatkan kualitas produk melinjo. Keaktifan wirausaha meningkatkan kualitas emping melinjo dimulai dari bahan baku. Mereka akan memilih bahan baku melinjo yang baik, biji yang sudah matang, keras tidak lembek dan tidak cacat biji. Biasanya biji melinjo yang cacat oleh karena serangga akan menimbulkan bekas warna hitam ataupun coklat pada emping melinjo. Selain itu wirausaha juga aktif melakukan pengembangan produk maupun pasar baru emping melinjo. Selain itu harga yang ditetapkan oleh pasar menjadi acuan para wirausaha untuk bermain harga dengan pesaing yang lainnya. Dimensi proaktif juga berpengaruh pada industri makanan dan minuman di Surabaya (Quantandana dan Haryadi 2015).

Industri pengolahan emping melinjo kurang adanya terobosan terkait produk maupun teknologi. Hal ini dikarenakan para wirausaha enggan beralih dari proses pengolahan manual dengan cara ditutu dengan teknologi terbaru (Bleeker 2011). pengoalahan emping melinjo dengan bantuan teknologi, akan tetapi hasil yang didapatkan kurang memuaskan. Emping yang dihasilkan lembek, mudah berjamur, dan tidak serenyah proses manual. Selain itu para wirausaha banyak yang tidak setuju dengan adanya olahan lain dari melinjo selain dibuat emping. Hal ini disebabkan pasar kurang minat dan prosesnya yang dirasakan kurang efisien (Pangeran2012). Hal ini karena inovasi yang terjadi karena orientasi kewirausahaan adalah inovasi yang berupaya untuk penyegaran, pembaharuan, dan redefinisi organisasi, pasar dan industri (Kumalaningrum 2012). Inovatif dalam penelitian ini dilihat dari usaha yang dilakukan dengan sesuatu hal yang baru, seperti produk baru, variasi rasa, penggunaan teknologi baru dan konsep pemasaran yang inovatif untuk menambah pasar. Berdasarkan fakta dilapangan bahwa industri pengolahan emping melinjo belum berani merubah pola yang sudah lama mereka lakukan. Wirausaha enggan untuk merubah bentuk emping melinjo yang sudah dari dulu berbentuk pipih bulat. Wirausaha enggan untuk berinovasi. 
Berani mengambil risiko yaitu kesediaan wirausaha untuk berani mengambil keputusan yang berisiko, seperti terjadinya kerugian pada usahanya atau berani menambah modal usaha dengan meminjam kredit. Wirausaha lebih suka memperhitungkan risiko pada pengolahan emping melinjo untuk menghindari risiko yang akan terjadi. Oleh karenanya para wirausaha selalu mencari cara untuk menghindari kegagalan seperti menangani ketersedian bahan baku selain itu bekerja keras untuk mengurangi risiko yang akan terjadi. Indikator selanjutnya yaitu otonomi dalam orientasi kewirausahaan pada industri pengolahan emping melinjo. Indikasinya yaitu melakukan proses pengolahan sesuai alurnya. Menerapan teknologi baru dilakukan secara perlahan. Dan dalam pengambilan keputusan dilakukan secara musyawarah sedangkan pimpinan menjadi menentu keputusan. Kenyataan dilapangan menunjukkan bahwa wirausaha emping melinjo menuturkan bahwa proses pengolahan emping melinjo ini sudah turun-temurun dari pendahulu. Indikator kelima yaitu agresif kompetitif dalam orientasi kewirausahaan industri pengolahan emping melinjo. Kriteria dari agresif kompetitif yaitu kemauan keras untuk mengalahkan pesaing, berusaha memperluas jaringan pasar untuk pendistribusian produk emping melinjo dengan berbagai pengorbanan. Kenyataan di lapangan ada wirausaha yang mengorbankan pendapatan dari usaha lain digunakan untuk memperluas pasar emping melinjo dengan menetapkan harga dibawah harga pesaing. Selain itu mengolahan emping melinjo dilakukan dengan efektif dan efisien untuk menekan biaya produksi, akan tetapi tetap mengedepankan kualitas untuk menunjukkan kompetitif dengan pesaing.

\section{Model Bisnis pengolahan melinjo}

\section{Customer segment}

Customer Segments yaitu segmen pelanggan yang menjadi target bisnis. Wirausaha pengolahan melinjo melayani segmen pelanggan yang biasa mengkonsumsi emping melinjo dengan beberapa sajian lainnya, misalnya soto, pecel atau nasigoreng di beberapa daerah di Indonesia, maupun dalam daerah Kabupaten Batang, dan luar daerah seperti Surabaya, Bali, Kalimantan, Jakarta dan ada beberapa yang sudah expor ke Dubai dan Malaysia. Mayoritas segmen pelanggan di Kabupaten Batang membeli produk olahan melinjo untuk konsumsi pada acara tertentu, sedangkan untuk luar daerah Kabupaten Batang mayoritas pelanggan membeli produk ini untuk dijual kembali ke retail langsung konsumen dan ada pula yang di ekspor. Customer segments dalam usaha pengolahan melinjo ini ialah berdasarkan mass consumer yang kebiasaannya konsumen yang mengkonsumsi emping melinjo dengan berbagai masakan.

\section{Value propositions}

Bisnis yang dijalankan para pengusaha pengolahan melinjo dengan menciptakan produk olahan melinjo menjadi beberapa jenis, diantaranya menjadi emping melinjo pipih kualitas super, biasa dan remahan kondisi mentah. Selain itu ada yang dalam bentuk emping melinjo kletuk rasa peda, manis dan tawar kondisi sudah matang. Para pengusaha mencoba untuk menghadirkan bermacam varian olahan dari melinjo. Mengutamakan kualitas yang baik pada emping melinjo untuk meningkatkan kinerja

3. Channels

Upaya menjangkau pelanggan, pengusaha melinjo menggunakan beberapa saluran pemasaran, diantaranya melalui direct selling/ pemasaran secara langsung dan indirect (tidak langsung). Pengusaha menjual produknya langsung ke konsumen akhir. Selanjutnya melalui saluran distributor, pengusaha menjual produk olahan berupa emping pipih dan emping kletuk kepada pedagang besar di Jakarta, untuk selanjutnya di jual ke luar negeri. Pengusaha hanya mensuplai produk kepada pedagang besar. Selain itu saluran pemasaran yang digunakan pengusaha melalui indirect dengan saluran daring melalui media sosial (online marketing), melalui saluran ini pengusaha menjual produknya kepada konsumen. 


\section{Customer relationship}

Pelanggan perlu dilakukan upadate secara intensif, upaya tersebut untuk menjalin hubungan baik dengan pelanggan. Pelayanan secara personal dapat meningkatkan penjualan olahan melinjo bagi pengusaha. Selain itu pengusaha memberikan kemudahan untuk pelanggan di dalam daerah Kabupaten Batang, dengan kemasan plastik $0.5 \mathrm{~kg}$ atau bisa ecer tanpa dus. Customer relationship diterapkan yaitu personal assistance dimana kustomer berkomunikasi langsung dengan pengusaha.

5. Revenue streams

Pemasukan utama para pengusaha hanya dari penjualan produk emping pipih dan emping kletuk. Ada beberapa yang menjual melinjo dalam bentuk biji (klatak) kepada mengrajin dengan sistem jual lepas.

6. Key activities

Aktivitas yang menjadi kunci para pengusaha melinjo yaitu aktivitas produksi dan pemasaran. Aktivitas produksi meliputi proses pengolahan biji melinjo menjadi emping. Prosesnya dari penyiapan bahan baku yang dilakukan dengan melihat stok biji di lingkup daerah kabupaten batang sendiri tersedia atau tidak, bila tidak ada stok biji melinjo maka pengusaha membeli biji melinjo dari luar daerah kabupaten batang seperti ke darah Banten maupun Lampung. Proses nutu (memipihkan biji), penjemuran, pemasakan dan sampai pada pengemasan emping melinjo. Aktivitas pemasaran adalah segala bentuk penjualan agar produk terjual, baik di promosikan secara langsung maupun online ke pelanggan.

\section{Key resources}

Produk emping melinjo meliputi tiga hal utama yang penting. Hal utama tersebut yaitu bahan baku, tenaga kerja dan pemasaran

8. Key partnership

Key partner usaha emping melinjo meliputi kelompok pengrajin, pengusaha kemasan dan pemasar. Key partners dengan pemerintah juga dilakukan untuk mendapatkan perizinan legalitas produk emping melinjo.

9. Cost structure

Cost structure dalam usaha emping melinjo adalah biaya variabel dan tetap, biaya investasi peralatan, biaya distribusi dan angsuran kredit pada beberapa pengusaha dalam menunjang berjalannya usaha.

\section{Tabel 2}

Business model canvas (BMC) pengolahan melinjo

\begin{tabular}{|c|c|c|c|c|}
\hline \multirow[t]{2}{*}{$\begin{array}{l}\text { Key partnership } \\
\text { 1. Pengrajin } \\
\text { 2.Pengusa- ha } \\
\text { kemasan } \\
\text { 3.distibu- tor }\end{array}$} & $\begin{array}{l}\text { Key Activities } \\
\text { 1. Produksi } \\
\text { 2. Pemasaran }\end{array}$ & $\begin{array}{l}\text { Value Propositi- } \\
\text { on } \\
\text { Performa-nce } \\
\text { (kinerja) }\end{array}$ & \begin{tabular}{||l} 
Customer \\
relation- ship \\
Konsumer \\
langsung
\end{tabular} & \multirow[t]{2}{*}{\begin{tabular}{|l} 
Customer \\
segments \\
Mass costumer1. \\
Lokal 2. Inter- \\
nasional
\end{tabular}} \\
\hline & $\begin{array}{l}\text { Key resources } \\
\text { 1. Bahan baku } \\
\text { 2. Tenaga kerja } \\
\text { 3. Pemasaran }\end{array}$ & & \begin{tabular}{||c} 
Channels \\
1.Direct \\
2.In- direct
\end{tabular} & \\
\hline \multicolumn{3}{|c|}{$\begin{array}{l}\text { Cost Structure } \\
\begin{aligned} \text { 1. } & \text { Biaya variabel } \\
\text { 2. } & \text { Biaya fix (tetap) }\end{aligned}\end{array}$} & \multicolumn{2}{|c|}{$\begin{array}{l}\text { Revenue stream } \\
\text { Penjualan produk }\end{array}$} \\
\hline
\end{tabular}




\section{Analisa SWOT}

Analisa SWOT pada bisnis pengolahan melinjo yang terdiri dari strenghts, weakness, opportunity dan threats dalam hal key partnership dimana komunikasi dengan konsumen, rekan kerja dan distributor baik. Selain itu tetap menjaga kualitas melinjo yang digunakan, harga yang kompetitif sesuai dengan kualitasnya. Sedangkan weakness pada revenue streams masih sebatas penerimaan dari penjualan produk, belum berkembang ke pelatihan maupun kunjungan dan penelitian. Cost structure yang tinggi untuk pembelian bahan baku dan distribusi. Key resources pada tenaga kerja nya masih rendah tingkat pendidikannya. Opportunity yang dimiliki ialah makanan khas yang tidak dimiliki banyak daerah dan digunakan sebagai campuran makanan lain. Dan kualitas dan ketahanan penyimpanan lebih baik dibandingkan dengan daerah lain. Threats yang ada dari konsumen yang memiliki selera yang beda dan isu terkait dengan kesehatan.

Tabel 3

Analisa SWOT bisnis pengolahan melinjo

\begin{tabular}{|c|c|}
\hline $\begin{array}{l}\text { Strenghts } \\
\text { Harga kompetitif } \\
\text { Kualitas terjaga } \\
\text { Komunikatif } \\
\text { dengan partner } \\
\text { kerja }\end{array}$ & $\begin{array}{l}\text { Weakness } \\
\text { Mengandalkan } \\
\text { pendapatan dari } \\
\text { penjualan produk } \\
\text { Bahan baku yang } \\
\text { mahal } \\
\text { Rendahnya tingkat } \\
\text { pendidikan tenaga } \\
\text { kerja }\end{array}$ \\
\hline $\begin{array}{l}\text { Opportunity } \\
\text { Makanan khas } \\
\text { Kualitas baik } \\
\text { Daya simpan lama }\end{array}$ & $\begin{array}{l}\text { Threats } \\
\text { Selera konsumen } \\
\text { Isu kesehatan }\end{array}$ \\
\hline
\end{tabular}

\section{Kesimpulan}

Berdasarkan hasil pembahasan analisa bisnis model kanvas pada bisnis pengolahan melinjo dapat disimpulkan bahwa, bisnis pengolahan melinjo memiliki customer segments yang lebar atau pasar yang besar baik lokal maupun internasional. Hubungan dengan konsumen secara langsung dan baik. Value proposition dengan mengedepankan kualitas untuk meningkatkan kinerja. Aktivitas utama bisnis pengolahan melinjo yaitu produksi dan pemasaran. Kerjasama dengan pengrajin, pengusaha kemasan dan distributor baik. Biaya yang digunakan yaitu biaya tetap dan biaya variabel dan satu-satunya pendapatan yaitu dari penjualan produk emping melinjo. Maka kekuatan dari bisnis pengolahan melinjo ialah harga kompetitif, selalu menjaga kualitas, dan wirausaha selalu berupaya menjaga komunikasi yang baik dengan partner kerja. Kelemahannya yaitu masih mengandalkan pendapatan dari satu sumber, bahan baku mahal, dan rendahnya tingkat pendidikan tenaga kerja. Peluang bisnis pengolahan melinjo diantaranya yaitu sebagai makanan khas, daya simpan bisa lama karena menjaga kulitas emping. Sedangkan ancamannya yaitu adanya isu kesehata terkait dengan konsumsi melinjo dan selera konsumen yang mudah berubah-ubah. 


\section{Daftar Pustaka}

Azhar, R. M., Suparno, O., \& Djohar, S. 2017. Business Model Analysis Of Lokawisata Baturaden With The Business Model Canvas. Manajemen Ikm 12 (2) , 137-144.

Bleeker, I. 2011. The Influence Of Entrepreneurial Orientation On The Innovation Process : An Empirical Research On Manufacturing Smes. Enschede: Thesis University Of Twente.

Haliq, I. 2017. Pengaruh Orientasi Kewirausahaan Terhadap Kinerja Usaha Peternakan Ayam Boiler Di Kabupaten Bogor. Tesis. Bogor: Sekolah Pascasarjana Ipb.

Irawan, D. 2015. Potensi Usaha Koperasi Dan Usaha Keccil Menengah Di Daerah Terisolir Dan Tertinggal. Coopetition, Volume 6 No 2, 51-62.

Istiyanti, E., \& Kamardiani, R. R. 2015. Koordinasi Supply Chain Management Emping Melinjo Di Kabupaten Bantul Daerah Istimewa Yogyakarta. Yogyakarta: Kopertis Wil V Diy.

Kumalaningrum, M. P. 2012. Lingkungan Bisnis, Orientasi Kewirausahaan, Orientasi Pasar Dan Kinerja Usaha Mikro, Kecil Dan Menengah. Jrbm Vol 7 No. 1 , 45-59.

Lumpkin, G., \& Dess, G. 2001. Linking Two Dimensions Of Entrepreneurial Orientation To Firm Performance: The Moderating Role Of Environment And Industry Life Cycle. Journal Of Business Venturing 16 (5) , 429-451.

Murni, T., Alhansji, T., Idrus, M. S., \& Arifin, Z. 2014. The Effect Of Entrepreneurial Orientation On The Management Capability And Sustainable Innovation (Study On Batik Small And Medium Enterprises In East Java Indonesia. Iosr Journal Of Business And Management 16 (4), 16-20.

Pangeran, P. 2012. Orientasi Pasar, Orientasi Kewirausahaan Dan Kinerja Keuangan Pengembangan Produk Baru Usaha Mikro Kecil Dan Menengah. Jurnal Riset Manajemen Dan Bisnis Vol, 7 No. 1, 1-15.

Priyono, F. 2015. Analisa Penerapan Business Model Canvas Pada Toko Moi Collection. Agora 3 (2) , 358-363.

Quantananda, E., \& Haryadi, B. 2015. Pengaruh Orientasi Kewirausahaan Pada Perusahaan Makanan Dan Minuman Di Surabaya. Agora 3 (1) , 706-715.

Rizani, N. A. 2015. Kapasitas Usaha Mikro Kecil Dan Menengah Dalam Pengembangan Ekonomi Lokal. Bogor: Laporan Studi Pustaka Institut Pertanian Bogor.

Rosmasari, I. A. 2019. The Effect Of Entrepreneurial Orientation On Melinjo Processing Industries In Batang Regency. Indonesian Journal And Entrepreneurship, 5 (2) , 148157.

Sugiono. 2011. Metode Penelitian Kuantitatif, Kualitatif, Dan $R \&$ D. Bandung: Alfabeta.

Sultan, R., \& Habi, I. 2018. Analisis Bisnis Model Kanvas Pada Kadatuan Koffie Bandung. Jurnal Manajemen Dan Bisnis (Almana) 2(2) , 116-123.

Sunendar. 2018. The Efficiency Of Melinjo (Gnetum Gnemon L) Chip Supply Chain In Bantul Regency Province Of Yogyakarta. Agro Ekonomi, 29 (2) , 207-217.

Tatefuji, T., Yanagihara, M., Fukushima, S., \& Hashimoto, K. 2014. Safety Assessment Of Melinjo (Gnetum Gnemon L.) Seed Extract: Acute And Subchronic Toxicity Studies'. Food And Chemical Toxicology 69 , 230-235. 
Urata, S. 2000. Policy Recommendation For Sme Promotion In The Republic Of Indonesia. Japan: Japan International Coorporation Agency. 